\title{
The Changing Paradigm in Preclinical Toxicology: in vitro and in silico Methods in Liver Toxicity Evaluations
}

\author{
Fozia Noor \\ Luxembourg Centre for Systems Biomedicine (LCSB), Université du \\ Luxembourg, Esch-sur-Alzette, Luxembourg \\ Fozia.noor@uni.lu
}

Toxicology in the 21st Century

Toxicology is one of the sciences that have slowly but surely embraced technology and new methods, focusing on high throughput and high content screenings, omics technologies, and mathematical modeling. Thus, a transition in toxicology_from a traditional reductionist paradigm towards 21st century methods based on human biology and holistic multi-omics studies-is now becoming a reality. With the recent advances in human-cell cultivation techniques, allowing in vivo-like in vitro long-term functionality, there is a shift in focus towards the mechanistic details of the adverse effects "over time" aimed at a better understanding of the dynamics of biological processes.

In vitro methods, based on human primary cells, cell lines, and genetically modified reporter cell lines, have greatly expanded the scope of in vitro toxicology. Other significant progress in the area of human-induced pluripotent stem cells (hipSCs) (Asgari et al., 2010; Schwartz et al., 2014; Shinde et al., 2016; Shtrichman, Germanguz and Itskovitz-Eldor, 2013) is allowing the application of patient and disease-specific hipsCs (Ghodsizadeh et al., 2010; McCracken et al., 2014; Siller et al., 2013). Moreover, the tools of precise genome editing with engineered nucleases, such as the zinc finger nucleases (ZFNS), the transcription activator-like effecter nucleases (TALENs) and, more recently, the Clustered Regularly Interspaced Short Palindromic Repeats (CRISPR) associated Cas9 technology (Gaj, Gersbach and Barbas, 2013; Kim, 2016; Komor, Badran and Liu, 2017) have opened up tremendous opportunities for the development of cell lines, especially those of human origin (Tobita, Guzman-Lepe and de L'Hortet, 2015). CRISPR/Cas9 technology was reported for genome editing in hipSCs (Flaherty and Brennand, 2015; Li et al., 2014; Seah et al., 2015; Suzuki et al., 2014). Another study reported on the simultaneous reprogramming and

(C) FOZIA NOOR, 2019 | DOI:10.1163/9789004391192_026

This is an open access chapter distributed under the terms of the prevailing CC-BY-NC License at the time 99004391192 of publication. 
gene correction of patient fibroblasts (Howden et al., 2015). Since 2015, more than 3,000 articles were published on studies using CRISPR/Cas9 genome editing, including more than 900 articles using the technology in mammalian cells (PubMed, accessed June 11, 2017). With further technological developments, these human in vitro cellular models shall be highly useful in the screening of compounds for personalized medicine, allowing optimum therapy with minimum or no adverse effects, and in the study of adverse outcomes in different strata of population. In addition to high-content screening, where several parameters are measured as simultaneous readouts in single cells (Gasparri, 2009), high-content imaging will play an important complimentary role in systems biology approaches (van Vliet et al., 2014). High-content platforms have been already used for the screening of compounds (Bale et al., 2014; Sirenko et al., 2014; Tolosa et al., 2014).

Modern technologies of omics and high-content imaging are resulting in immense data sets which require large-scale data-processing tools. Powerful bioinformatics' tools are also required for data integration and the overarching interpretation of biological data from disparate sources. The inherent complexity of biological systems is a challenge that is expected to be overcome by computational modeling of biological systems. Toxicology is, therefore, aiming at the integration of a tremendous amount of diverse information - at various levels of biological hierarchy (genome, transcriptome, proteome, and metabolome) and biological structure (organelles, cells, tissues, organs, and organism) - with computational tools for understanding and predicting biological behavior (e.g., adverse effect) under given conditions (e.g., perturbation due to a toxin). This rejuvenated toxicology in modern terms is referred to as systems toxicology (see Figure 25.1).

\subsection{Systems Toxicology}

The term systems toxicology is derived from systems biology and could be defined as the study of biological systems, using omics technologies, with a focus on the mechanisms underlying complex biological processes, their interactions and perturbations in response to a toxin combined with mathematical data integration and modeling. Systems toxicology, therefore, aims at understanding and exploring the way that different biological components are orchestrated as an ensemble in cells, tissues, and organisms.

A biological system usually consists of a large number of functionally diverse and/or multitasking components interacting together in a nonlinear fashion in, so-called, biological networks spread over several levels of biological organization (Kitano, 2002). Systems biology aims at understanding the structural and functional connectivity in biological networks or simply the biological 


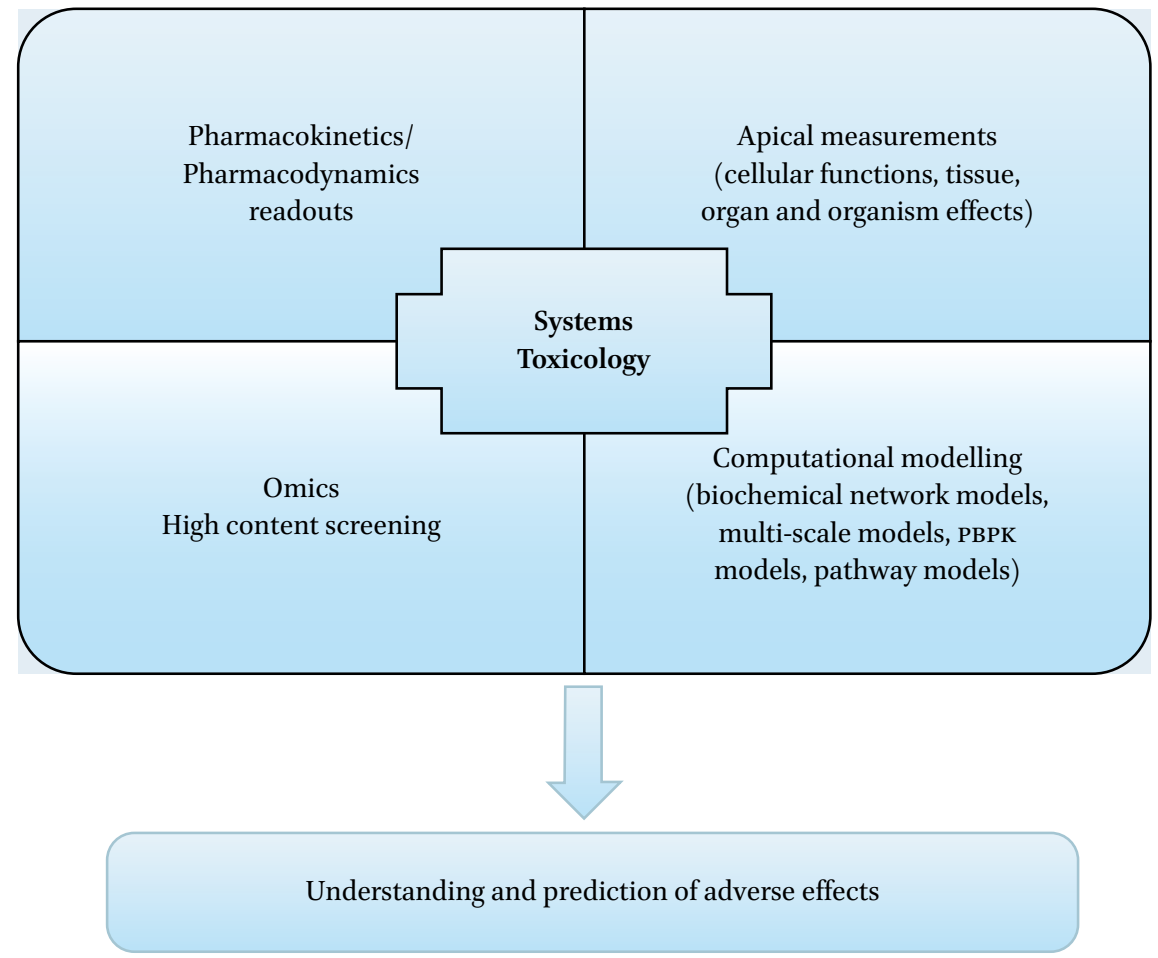

FIGURE 25.1 Modern toxicology leaning towards the systems biology approach to understanding and predicting adverse effects by integrating traditional endpoint measurements and pharmacokinetics/pharmacodynamics information with omics data and computational modeling.

homeostasis. Almost 150 years ago, the French physiologist, Claude Bernard, put forward the idea that free life is based on the constancy of the internal environment. Later, in 1922, the American physiologist, Walter Canon, described homeostasis as the key principle of life. According to Hans Seyle (1956), since systems are robust, a system under stress will try to achieve a new homeostasis to maintain its functions, until the stress crosses a certain threshold, and the system collapses. Similarly, biological systems exposed to a stressor/toxin will try to adapt and survive. Acute exposure for a short period may constitute a temporary stress that may, or may not, manifest as a toxic effect(s), while the biological system tries to adapt or compensate. However, acute exposure at a very high dose may lead to acute exhaustion of the system's resources to cope and may lead to rapid system breakdown. On the other hand, upon repeated or chronic exposure to low levels of stress, the system inevitably acquires a new homeostasis. This new homeostasis may be accompanied by adverse effects 
or disease development (e.g., depression, cancer) over the period of exposure. Upon accumulation of long-term stress, when the system's capacity to maintain altered homeostasis is exhausted, the system will break down, ultimately leading to the extinction of the system.

Understanding biological processes means a step towards understanding the mechanisms of adverse effects, which in turn means understanding the molecular and functional changes in a system upon perturbation of the system's homeostasis. A mechanistic understanding requires system-wide quantitative measurements of these molecular and functional changes. Recent progress in omics technologies is playing a decisive role in linking system-level understanding to quantitative molecular knowledge (Ideker, Galitski and Hood, 2001). An essential part of systems toxicology is the mathematical modeling of biological responses based on mechanisms and the use of such computational models for predicting responses by changing the parameters of perturbation. Systems toxicology is, therefore, the integration of traditional toxicology with modern techniques of integrated testing strategies, high-throughput screenings, pharmacokinetics/pharmacodynamics knowledge, high-content screenings, omics technologies, in silico tools and modeling. Recent advances in cell-culture techniques, mimicking in vivo organs, are allowing for the acquisition of physiologically relevant information that will enhance pathways-based understandings for the discovery of novel targets and prediction of risks of adverse outcomes.

\subsection{Pathways of Toxicity}

The concept of pathways of toxicity (PoTs) evolved after the famous report from the United States National Research Council in 2007, titled Toxicology in the 21st Century, which recommended a shift in testing from animals to human-cell systems for the assessment of toxicity pathways (Krewski et al., 2010). Other terms, such as the mode of action (MOA) and the adverse outcome pathways (AOP) are currently used to structure and describe biological processes over biochemical pathways leading to adverse effects. This information can be mapped on various levels of biological organization (e.g., from cells to populations and even ecologies) (see Figure 25.2).

A PoT is a cellular response pathway, which upon sufficient perturbation will lead to an adverse health effect. A PoT should describe the molecular basis of the adverse response. It is assumed that a limited number of PoTs are conserved over cell types, organs, and even species, and should mediate the same adverse outcome (Bouhifd et al., 2015). PoTs aim at molecular annotations of network perturbations and their causes from high-content phenotyping (Hartung and McBride, 2011). It should be possible to derive PoTs from simple invitro tests, as in the ToxCast program in the Us, which evaluated 2,00o compounds 


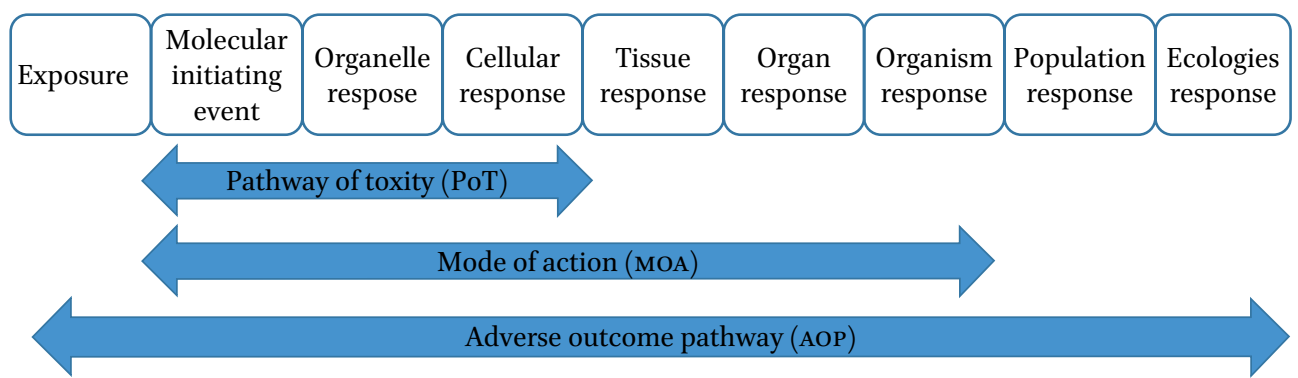

FIGURE 25.2 Organization of scientific information at different levels of biological complexity with commonly used terminologies, such as PoT, MOA, and AOP. ADAPTED FROM GOCHT ET AL. (2015)

in more than 700 assays and around 300 signaling pathways (Attene-Ramos et al., 2013; Hsieh et al., 2017).

The molecular mechanisms over a series of causal events can be described as the MOA. It is important to distinguish a mechanism of action from the mode of action. A mechanism of action describes the primary chemico-biological interaction between a compound and a structural moiety in a biological system (Blaauboer and Andersen, 2007). This is more or less equivalent to the molecular initiating event in an AOP. The MOA describes functional and structural changes that follow the primary interaction of a compound with its biological target and result in quantifiable changes at the organism level (Blaauboer and Andersen, 2007). The MOA-based paradigm is based on the concept of toxicity pathways. A PoT represents a set of molecular events that ultimately lead to a measurable adverse outcome associated with the stressor/toxin. As such, MOA and AOP are sometimes used in similar contexts.

\subsection{Adverse Outcome Pathways}

The concept of AOP was developed in the field of ecotoxicology. Ankley et al. (2010, p. 730) defined AOP as "a conceptual construct that portrays existing knowledge concerning the linkage between a direct molecular initiating event and an adverse outcome at a biological level of organization relevant to risk assessment". The term AOP is a misnomer, since pathways are not intrinsically adverse or non-adverse but they may lead to adverse effects or disease after perturbation. The AOP framework allows the organization and structuring of information for improved decision making in risk assessment (Edwards et al., 2016).

The concept of AOP is now embraced by scientists all over the world, with international efforts for harmonization and guidance on AOP construction and development, such as the Organisation for Economic Co-operation and Development (OECD) guideline (2013) and recently published AOP development strategies, principles, and best practices (Villeneuve et al., 2014a,b). AOPs have 
been described for skin sensitization, liver cholestasis, liver steatosis, and fibrosis (OECD, 2012; Vinken et al., 2013; Willett et al., 2014). More recently, there are suggestions that the AOP framework can also be used for organizing, structuring, and describing the pathways involved in diseases (Langley et al., 2017; Noor, 2015).

An AOP will begin upon exposure to a compound. The interaction of that compound with the biological target will depend on its physico-chemical properties and could be analyzed using methods of quantitative structureactivity relationships (QSARs). The interaction of the compound with its biological target is the molecular initiating event. This will in turn lead to causal chain of events at different levels of biological organization, with effects at the organelle, cellular, and tissue levels. Depending on the intensity and duration of the exposure, these effects will affect the function(s) of the organ, which will initially try to adapt to the perturbation to achieve a new homeostasis. However, persistent stress will ultimately lead to adverse effect(s) at the organ level (see Figure 25.3). With time, organ level effects can spread to the whole organism. In epidemiology, many affected organisms will lead to population and ecology effects.

Initially, AOPs were thought to be linear constructs with key events causally linked with each other and occurring at different levels of biological organization (Landesmann et al., 2013). However, biological systems are highly complex and interconnected, in addition to being very robust, and show adaptive responses to stress stimuli. Biological processes are nonlinear and highly wired together with feedback loops and cross regulation. Modern AOps are chemically independent, modular, and connected over networks (Villeneuve et al., 2014a). The concept of key event relationships has been used to explain quantitative connections between several AOps and more than one adverse

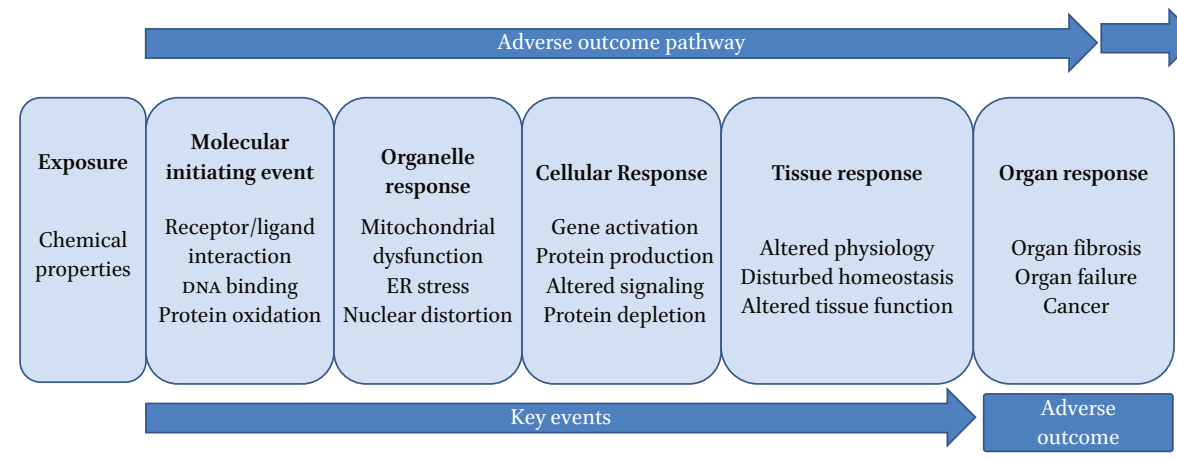

FIGURE 25.3 An AOP framework to explain multilevel effects beginning with an initial triggering event (molecular initiating event), followed by a series of intermediary events (key events) that lead to an adverse outcome.

ADAPTED FROM LANDESMANN ET AL. (2013) 
outcome (Figure 25.4). These connections help to identify gaps and uncertainties in an AOP. An adverse outcome may also lead to another adverse outcome. For prediction, quantitative response relationships among key events within an AOP are required and make use of weighting and probabilistic and mechanistic approaches (Becker et al., 2015; Perkins et al., 2015). It is expected that quantitative $A O P$ and quantitative AOP networks will have quantitative key event relationships and this may help define an $A O P$ score for the prediction.

Although an AOP is a pragmatic way of organizing information of biological relevance and facilitates causal links with multilevel information, there are many challenges to their wide application. An AOP should not only give information about the structure of the system but also provide important clues

A
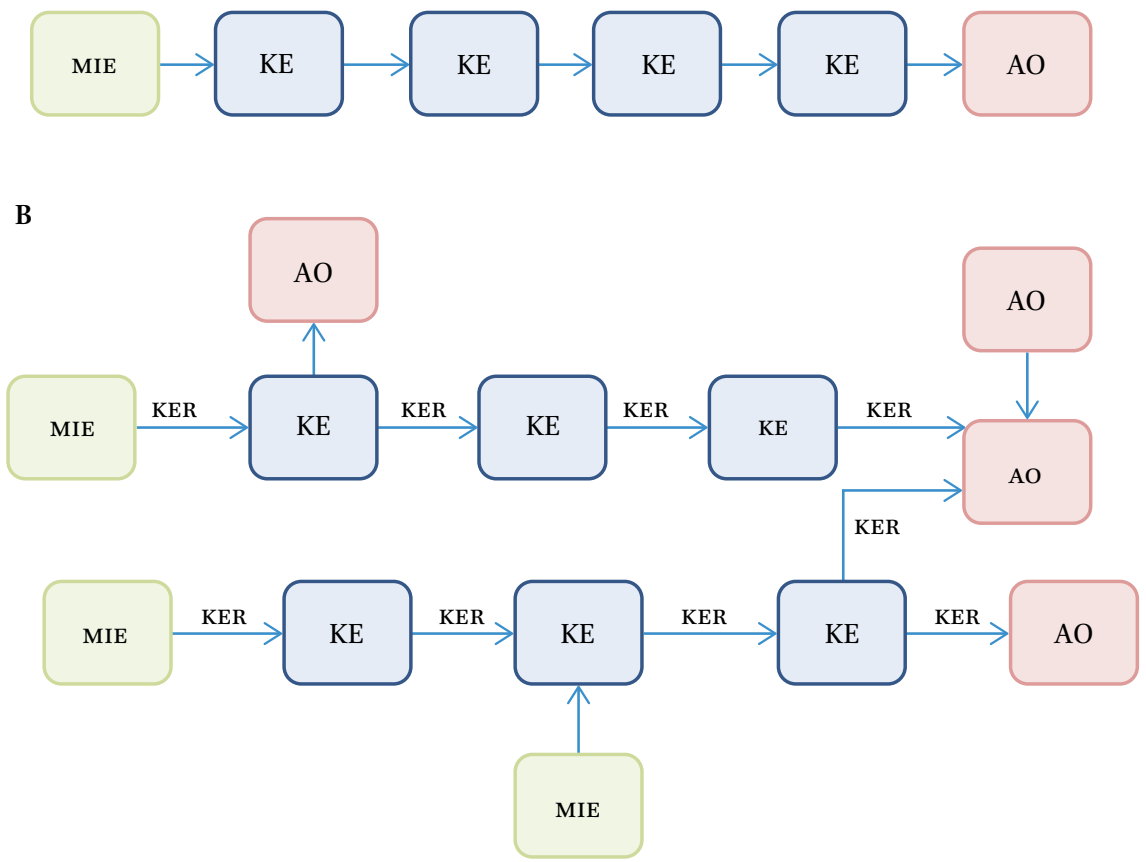

FIGURE 25.4 Adverse outcome pathways. (A) a linear AOP showing molecular initiating event (MIE) as the interaction between chemical and its biological target leading to a chain of causal key events (KE) resulting in an adverse outcome (AO). (B) an AOP network with multiple pathways and key events (KE) leading to one or more adverse outcomes. The quantitative correlation between two key events (KER) would determine the intensity of the involvement of that pathway.

ADAPTED FROM GARCIA-REYERO 2015 
on the dynamics of the system. It is highly recommended for an AOP to have direct human relevancy, and an AOP based only on animal data is insufficient. The relationships between molecular initiating events, key events, and adverse outcomes should be predictable. The successful application and adaption of AOPs in toxicology (especially regulatory toxicology) will depend on the effectiveness of an AOP to predict adverse outcomes. Since AOPs are considered living documents that will change with the progressive availability of knowledge, the development of AOPs will proceed in parallel with their use; which will inevitably, in some cases, pose uncertainties. The more nonlinear linkages there are over multiple pathways, the more challenging the task of deriving correlations for prediction. As with other sciences, there is an urgent need for standardization, harmonization, and development of common language(s) to connect and understand different application domains.

\section{Preclinical Drug Development}

From the discovery of new therapeutic entities to the marketing of the final product, the drug development process mainly deals with preclinical development and clinical trials of, so-called, investigational new drugs. Preclinical drug development focuses on the proof of efficacy and safety of new drugs. The immense technological advancements of recent years have rendered the drug discovery and development process more expensive than ever. At the same time, the success rates have fallen, the regulatory requirements are becoming stricter, and the competition has become fierce. According to the Tufts Center for the Study of Drug Development, in 2014, the cost of drug development was around us $\$ 2.6$ billion, with preclinical development costs surpassing us $\$ 1$ billion (Mullin, 2014). Only one in ten drugs entering the clinical phase is approved by the us Food and Drug Administration (FDA), according to a recent report (Hay et al., 2014). The failure of an investigational new drug in the clinical trials may cost billions of dollars (Horton 2004; Lang 2005). Most investigational new drug failures are due to lack of efficacy and/or clinical toxicity. Human safety issues result in about $20 \%$ of failed drugs (Kola and Landis, 2004). In 2010, a 10-year survey showed that safety issues remained one of the major bottlenecks in drug development (Waring et al., 2015). The woes of the pharmaceutical industry can continue even after the approval and marketing of a drug, as there is around $5 \%$ risk of post-marketing withdrawal due to adverse effects (Smith and Schmid, 2006).

Liver and cardiac toxicity are the major issues in drug development. Liver toxicity alone (until 2014) has resulted in most drug withdrawals. The 
regulatory agencies require the testing of acute and repeated-dose toxicity in animals. Although, the pharmaceutical industry is, at present, using a range of high-throughput in vitro assays (some accepted by regulatory bodies) in the initial screening of compounds, there are no accepted in vitro models for repeated-dose, long-term toxicity. The next part of the chapter focuses on the limitations of animal models and emerging new models and technology in the assessment of liver toxicity, followed by in silico computational methods in drug development.

\section{Limitations of Animal Models in Liver Toxicity Evaluations}

Although in vivo animal testing gives direct evidence of toxicity in a living "intact" organism and allows experiments not possible in humans, it is limited by several serious drawbacks of scientific, economical, and ethical nature. A major limitation is the poor predictive power of animal studies. This poor translation of animal results to humans is mainly due to species-specific differences (Martignoni, Groothuis and de Kante, 2006). Animals predict only $40 \%$ of human liver toxicities (Ewart et al., 2014; Olson et al., 2000). Even among different animal species, the correlation is about 6o\% (Hartung and Daston, 2009), showing differences among test species and the limitation of prediction. The intrinsic differences in animals within the same species provide inconsistent results, especially in the case of oral-dose chronic toxicity. Testing in animals is usually carried out in the highest tolerable doses, which do not reflect human exposure. Equally important, even after standard animal testing, $19 \%$ of compounds presumably safe in animals, show toxic effects in human clinical trials and are not pursued further (Sacks et al., 2014). In addition, many drugs proved safe in animal tests and clinical trials, are withdrawn from the market or labeled with black box warnings due to serious side effects. In the past 60 years, there have been more than $45^{\circ}$ post-marketing withdrawals of drugs due to hepatotoxicity (Onakpoya, Heneghan and Aronson, 2016).

Species-specific differences are mainly due to differences in the pharmacokinetic parameters, namely absorption, distribution, metabolism, and elimination. Screening in animals is carried out with the assumption that similar reactions of biotransformation and clearance will occur in animals as in humans. However, animals differ from humans in the biotransformation of xenobiotics from Phase o (uptake of compounds mainly via transporters), to Phase I (CYP450 metabolism), Phase II (conjugation reactions), and Phase III (excretion/eliminations of the parent compound or metabolites or their conjugates mainly via the transporters). It is now well known that not only are there 
differences in the metabolism of substances between animals and humans, but also many molecular mechanisms of human cellular injury are different (Woolbright et al., 2015).

In addition, due to the characteristics inherent to in vivo testing, such testing is excessively precautionary; and, therefore, many potential therapeutic compounds are screened out. One such example is aspirin, which is considered safe for human beings; it would not have been possible to market aspirin with current methods and criteria for safety (Hartung, 2009). This means that the current methods of screening may also possibly screen out compounds that could otherwise be useful in the therapy of human ailments. Other technical limitations include, low throughput of animal studies, in addition to prolonged study periods in some cases (e.g., carcinogenicity study) (Bucher, 2002).

Although animal testing has provided significant insights into biological processes and has contributed to human safety, the scientific goal of the 21st century should be a move towards human-based in vitro methods, with modern tools of systems biology, to bypass the species barrier and to allow better translation.

Traditionally, in vitro models refer to cell-cultivation methods of primary cells and cell lines, commonly involving plastic or glass cultivation vessels with a cell-culture medium suitable for a given cell type. Wilhelm Roux, a German zoologist, established the basic principles of tissue culture in 1885 , by maintaining tissues in a warm saline solution for several days. Julius Richard Petri, a German microbiologist, owns the credit of inventing the Petri dish in the early 190os. Modern two-dimensional $(2 \mathrm{D})$ cell culture is usually carried out in polymer culture flasks and dishes of multitude formats. Ross Granville Harrison, an American embryologist, is considered the pioneer of $3 \mathrm{D}$ cell culture using the hanging drop method (Nicholas, 1961).

Today, $2 \mathrm{D}$ cultivation techniques are well established and cells (mostly cell lines) of almost all tissues of human or animal origin are available. There are many advantages to the $2 \mathrm{D}$ cultivation of cells, such as simplicity; expertise required; low costs; high number of replicates; and, most importantly, application in high-throughput screening in multi-well plates, with the possibility of miniaturization and robotic automation, minimizing human bias and error as well as ensuring high precision. In addition, less material (cells and culture media as well as test substance) is required with fewer ethical concerns. A battery 
of simple and complex $2 \mathrm{D}$ in vitro assays can predict up to $80 \%$ of human hepatotoxicity (Noor et al., 2009; Vernetti et al., 2017).

Nevertheless, $2 \mathrm{D}$ cultivation of cells involves maintaining the cells in an unnatural and artificial environment, whereby they lose their organ- and tissue-specific architecture and organization. Other factors, such as medium change, cell density to surface ratios, lack of flow and sheer tension, and unphysiological oxygen supply are other major limitations. Another commonly encountered problem is the rapid de-differentiation of primary cells, such as the hepatic cells, in $2 \mathrm{D}$ cultures, resulting in the loss of functions.

In vivo, cell-to-cell contacts and communication across the extracellular matrix are ensured within a three-dimensional $(3 \mathrm{D})$ arrangement. The extracellular matrix regulates cell morphology and gene expression in vivo (Bissell, 2007; Bissell, Hall and Parry, 1982; Le Beyec et al., 2007). A 3 D environment influences the epigenetic plasticity of the cells (Spencer,Xu and Bissell, 2007; Xu, Spencer and Bissell, 2007). Conventional $2 \mathrm{D}$ hepatic cultures rapidly lose liver-like functionality (Godoy et al., 2013; Paine and Andreakos, 2004), leading to poor concordance between experimental in vitro data and in vivo data, especially with respect to xenobiotic metabolism and transporter activities. Optimization of the culture medium may help in the maintenance of functions for some time (Klein et al., 2014; Mueller et al., 2012). However, modern in vitro methods are more and more focused on the $3 \mathrm{D}$ cultivation of cells as organoids or micro tissues that ensure cell-to-cell contacts, cells to be surrounded completely by extracellular matrix, facilitating cell-to-cell communication and signaling (Alepée et al., 2014; Mueller, Heinzle and Noor, 2013).

${ }_{3} \mathrm{D}$ cultures of primary human hepatocytes and human-cell lines, such as HepRG and $\mathrm{HepG}$, retain long-term viability and maintain liver-specific functions in vitro (Mueller, Koetemann and Noor, 2011a; Mueller et al., 2011b; Gunness et al., 2013; Mueller et al., 2014; van Grunsven, 2017).3D cultures (also called ${ }_{3} \mathrm{D}$ micro tissues, organoids, and organotypic cultures) in microfluidic devices, are termed biochips (Baudoin et al., 2007), organs on a chip (Bhatia and Ingber, 2014) or body on a chip, where several tissues or organ systems are represented (Marx et al., 2012; Materne et al., 2015a; Materne et al., 2015b; Sung et al., 2014). These emerging technologies allow the study of human physiology and adverse effects in vitro, as they enable analysis of the biochemical and metabolic activities of living cells in functional tissue and organ contexts, while allowing high-resolution, real-time imaging (Bhatia and Ingber, 2014). Although, such advanced $3 \mathrm{D}$ culture techniques demand expertise, and usually special equipment/setups, in addition to comparatively higher costs and lower throughputs, they seem to be indispensable for meaningful humanbiology based science in future. 
Much development effort is underway for a high-throughput generation of the ${ }_{3} \mathrm{D}$ cultures as aggregates (Gevaert et al., 2014), micro-patterned co-cultures (Khetani and Bhatia, 2008) and $3 \mathrm{D}$ printing (Billiet et al., 2014). High-content platforms are already used in drug development for the screening of compounds (Bale et al., 2014; Tolosa et al., 2014). At the same time, highly-advanced imaging and other techniques (including automated methods for assessing multiple readouts, such as cell viability, shape of the nuclei, cell area, mitochondrial membrane potential, phospholipids accumulation, cytoskeleton integrity, and apoptosis) are playing an important role in the study of biological pathways (Ramaiahgari et al., 2014; Sirenko et al., 2014). Such high-content and high-throughput platforms are changing the toxicity screening paradigm (Patlewicz et al., 2013), paving the way towards pathway-based, in vitro only, safety assessment (Adeleye et al., 2014; Kleensang et al., 2014).

\section{5}

\section{Computational in silico Tools}

In silico methods such as quantitative structure activity relationships (QSARs) in predictive toxicology are not new. More than 150 years ago, Cros (1863) linked the toxicity of primary alcohols to their water solubility. Crum-Brown and Fraser (1869) advanced the idea that the biological activity of a compound was linked to its chemical structure. In the 1980s, when pharmaceutical companies were creating libraries of thousands of compounds, methods of QSARs were refined, automatized, and extensively applied. The idea was that the toxicity of a chemical is dependent on specific features of the structure of that chemi$\mathrm{cal}$. Therefore, similar chemical features are expected to share similar mechanisms of action and could be used for the prediction of activity. Basically, a set of compounds of known activities are used to train computer algorithms to differentiate between active and inactive compounds (Johnson and Maggiora, 1990). QSARs provide a mathematical relationship between a biological activity and one or more molecular descriptors able to predict the activity. These molecular descriptors are quantifiable and, therefore, give a quantitative relation to the toxicity. Modern QSARs are multidimensional (mQSAR) and include multiple representations of the ligand or protein (Tseng et al., 2012; Vedani, Dobler and Lill, 2006).

QSARs are often used in combination with other methods, such as read-across and weight-of-evidence assessments. Read-across is defined by the European Chemicals Agency (2017, p. 6) as "a technique for predicting endpoint information for one substance (target substance), by using data from the same endpoint from (an)other substance(s), (source substance(s))". A range of in silico 
tools are available for grouping the chemicals and read-across (Enoch, Cronin and Ellison, 2011). Publicly available software include, toxicity estimation software tool (TEST), the OECD QSAR toolbox, high-throughput virtual molecule docking (HTVMD), MetaCore, and the TOPKAt model. QSAR methods are increasingly predictive in hazard identification for acute toxicity, genotoxicity, mutagenicity, and bioaccumulation. Nevertheless, QSARs and read-across are limited in the prediction of the pharmacokinetic properties of compounds.

Other in silico methods include computational methods for modeling the pharmacokinetics of compounds and linking this to the biological response. Pharmacokinetics deals with the quantification of drug absorption, distribution, and elimination for the investigation and prediction of blood concentration-time profiles. Pharmacokinetic models can be simple to complex, depending on the level and the quality of information available. Simple models are empirical and can be used for the estimation of clearance and half-life, allowing dosage-regimen calculations (Jones, Mayawala and Poulin, 2013; Klein et al., 2015; Wetmore et al., 2012). Models that are more complex are Physiologically Based Pharmaco-Kinetic (РВРК) models, which are compartment models. These compartments represent tissues and organ spaces and their volumes. As early as 1937, Toerell, one of the pioneers of pharmacokinetics, described the basic principles of a РВ PК approach (Teorell, 1937). However, its mathematical complexity and the lack of physiological data needed for the model were significant challenges to its widespread application for many years.

At present, РВРК models are mechanism based and allow extrapolation from high doses to lower doses, from one species to another, and between dose routes. Traditionally, data is generated from in vivo animal and in vitro animal and human studies (see Figure 25.5), in an approach originally described by Sobels for anticancer drugs (Sobels, 1977).

Since PBPK models are based on physiological parameters, it is possible to use them to predict in vivo absorption, distribution, metabolism, and excretion. PBPK modeling is still heavily dependent on animal studies, and very few clinical applications of PBPK models have appeared. The major reason is the lack of human data for validation. However, in vitro systems can be used, to some extent, for the prediction of distribution, metabolism, and elimination (Poulin, 2013; Poulin et al., 2013a, b; Poulin and Haddad, 2013). Using а Рв РК model, in vitro tests can also provide parameters that allow the prediction of dose-response in vivo. Рв РК modeling not only allows simulation of human pharmacokinetics, it also enables in vitro to in vivo extrapolation. For this purpose, quantitative in vitro data, such as data on tissue distribution, rates of metabolism, rates of interactions with biological macromolecules such 


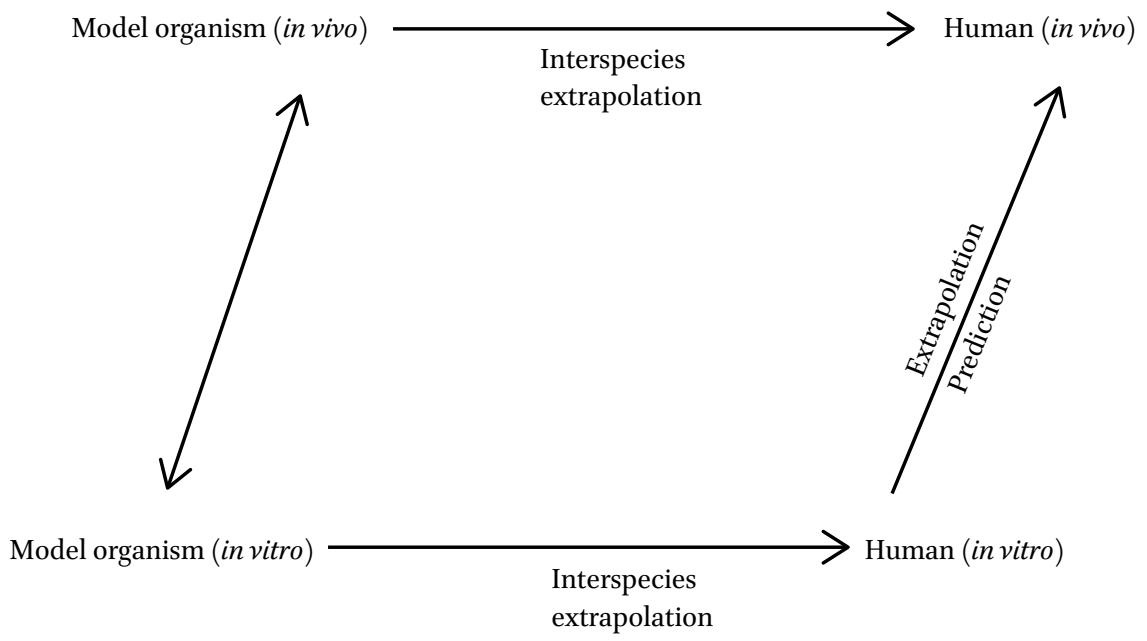

FIGURE 25.5 Traditional approach for risk assessment using animal data. ADAPTED FROM SOBELS (1977)

as receptors, changes in cell function and viability, is needed. PBPK modeling combined with other in silico (chemical-related) and in vitro (biologyrelated) parameter estimations allows for prediction of in vivo exposure equivalent to the in vitro assay concentrations producing an adverse effect. For reliable predictions using such methods, a thorough experimental design with the characterization of the biological system, including the cell model and its characteristics, is essential. Recently, simple РвРК models were combined with acute and long-term dose-response data to calculate oral equivalent doses (Chang et al., 2015; Hamon et al., 2015; Klein et al., 2015; Rotroff et al., 2010; Wetmore et al., 2012; Yoon et al., 2014).

Models based on a systems biology approach are also being developed (Ideker et al., 2001) to allow firm anchorage of РВРК/pharmacodynamic models on a mechanistic basis. This new developing area, currently also referred to as quantitative systems pharmacology, focuses on the drugability of targets in biological systems. Quantitative systems pharmacology, in fact, follows a systems biology approach to drug discovery, aimed at the underlying mechanisms of drug actions on multiscale systems, using iterative computational modeling (Knight-Schrijver et al., 2016; Vernetti et al., 2017).

In general, the advantages of in silico methods are low costs, standardization, equipment needs, throughput, and the tremendous possibility of virtual expansion in terms of chemical space, numbers, and biological response scenarios. However, these methods have their own limitations, such as reliability 
and robustness. These limitations are mainly based on data quality (and in some cases quantity) and the complexity of biological systems. Gene expression and metabolic network models, along with integrated, large multiscale models, are computationally demanding, data intensive, and time consuming.

\section{6 \\ Toxicology in the Coming Years: Challenges and Perspectives}

Systems biology - with next generation technologies, such as integrated omics techniques, advanced cell-culture methods, and assays, along with better and faster computational in silico methods-is playing a key role in changing the global mindset towards toxicology. This shift in paradigm will allow for the integration of a human knowledgebase, including network information and in vitro assays providing critical key event parameter values, with less emphasis on in vivo animal data (Edwards and Preston, 2008). For optimal application of systems biology tools, the fundamental construct is to develop adequate and fit-for-purpose in vitro assays to characterize pathway perturbations and predict adverse outcomes due to these perturbations. Future in vitro assays will be based on human cells derived from pluripotent stem cells and human reporter cell lines.

The two most important corner stones of risk assessment are exposure and concentration response. Systems biology provides the framework for bridging exposure to a compound and its causal adverse outcome (Sheldon and Cohen Hubal, 2009). It is essential that in vitro data provide relevant information on the concentration response over time. The perturbations and the concentration in which they occur should reflect human in vivo exposure and effects. However, extrapolation of in vitro results to humans in vivo is sometimes limited due to the fact that nominal concentrations in the in vitro assays are used without consideration of the exposure magnitude, timing, and duration (Coecke et al., 2013). Other factors such as in vivo bioavailability and metabolic clearance are not taken into account, in addition to other in vitro specific parameters, such as plastic binding, cell-surface binding, compound degradation and evaporation (Groothuis et al., 2015).

Furthermore, better tools for the characterization of the biological perturbations leading to adverse effects are needed for a mechanistic understanding of the perturbed pathways. This will require a recapitulation of the toxicity pathway(s) by in vitro assays. In this context, the systems biology approach provides molecular information and key event networks for the comparison of MOA-based pathways. Systems biology measurements will also provide information on overlapping events across multiple pathways. Given that there is often a temporal shift in various omics readouts, it is imperative to conduct 


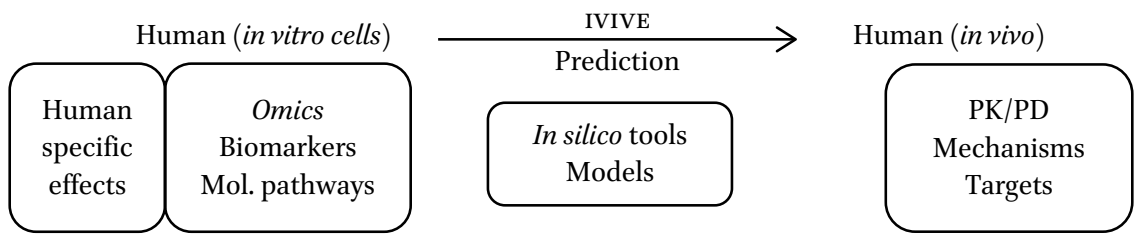

FIGURE 25.6 An ideal shift in paradigm where human-relevant, advanced mechanismbased in vitro cells, such as primary human hepatocytes, hipsCs, derived functional hepatocytes, or cardiomyocytes will provide high-quality data for in vitro to in vivo extrapolation (IVIVE) of human pharmacokinetics ( $\mathrm{PK}) /$ pharmacodynamics (PD), identification of targets, and mechanisms that will ultimately lead to the prediction of adverse effects in humans in vivo.

kinetic studies, so that time resolved data could be obtained. Careful design and control of the system is necessary to obtain high-quality data and to reduce uncertainties inherent to in vitro systems. A fully integrated systems approach would reduce many uncertainties associated with current risk assessment approaches. The aim is to obtain human-specific, high-quality data at different molecular levels and integrate these with in silico tools for the extrapolation and prediction of human adverse effects (see Figure 25.6).

Thus, a systems biology approach could help define MOA, species extrapolation, in vitro to in vivo extrapolation and provide a mechanistic basis for describing the susceptibility of certain subpopulations. An integrated approach of human in vitro and in silico methods for in vivo exposure is expected to provide a reliable prediction of toxicity. An in vitro system that is designed and characterized to provide human in vivo relevant information will be the key to successful prediction. Combined with qualitative and quantitative knowledge on perturbations in biological pathways over time, this integrated approach could be a powerful tool for in vivo relevant toxicity assessment. Finally, the concept of AOP remains to be developed beyond its limitations and deficiencies to be successful and to gain acceptance by the regulatory agencies in humanrisk assessment.

Microfluidic systems, using $3 \mathrm{D}$ organotypic cultures for compound screening, is another area with great promise. In the case of liver, it will additionally allow measurements of pharmacokinetic and pharmacodynamic parameters in vitro. A challenge will be to include more than one organ on such a platform. Although some systems (see Figure 25.7) are already reported, they are still limited in their wide application. A pragmatic solution will be to combine organ-type cells, according to the scientific need and the data needed.

The establishment of complex cellular models based on co-cultures is another active research area with promise in the quantitative understanding of mechanisms in human health and disease. Organs are complex structures and 


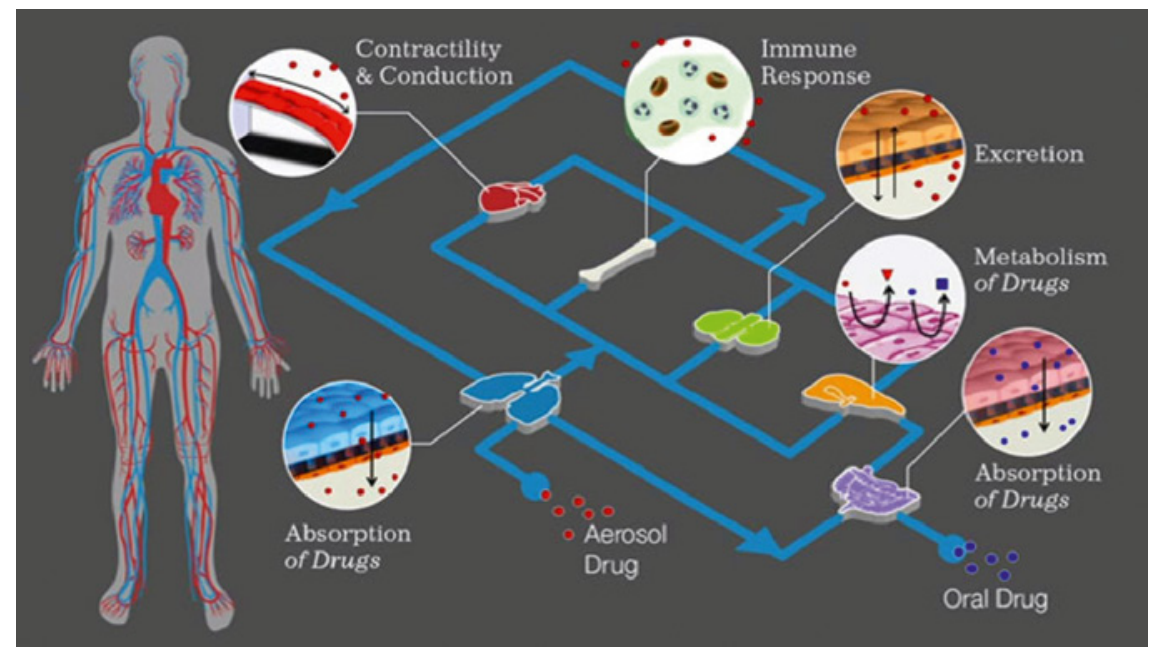

FIGURE 25.7 Body on a chip.

IMAGE COURTESY OF THE WYSS INSTITUTE, HARVARD UNIVERSITY

their response (manifested as adverse effects or disease) is a joint response of many cell types in communication. Combining different cell types is no trivial task, due to the complex environmental needs of each cell type. The in vivo relevance of these systems will have to be validated. Advanced microfluidic systems, in future, will include liver zonation (Vernetti et al., 2017).

The application of hipsc-derived models in human disease research, in future, will move in vitro systems from mostly proliferating cell lines towards patient-specific cells and will, thus, facilitate personalized systems medicine. Human-induced pluripotent stem cells have great potential in toxicological screening, since they provide patient-specific pharmacological responses. Hepatocyte-like cells, derived from hipscs cultured on a micropatterned coculture system are reported to predict the hepatotoxicity of test compounds with $65 \%$ sensitivity and $100 \%$ specificity (Ware et al., 2015). In addition, CRISPER/Cas9 technology provides a range of modified induced pluripotent stem cells (iPSCs), which will allow discovery of novel targets and biomarkers. A whole range of modified iPsCs, after differentiation, could serve not only in regenerative therapy but could be applied in mechanistic research and in the screening of therapeutics (see Figure 25.8).

It is hoped that this shift in paradigm will progress towards evidence-based science and personalized medicine, where clinical observations will be used to design advanced in vitro methods based on ${ }_{3} \mathrm{D}$ models, with patient-specific primary or iPSC-derived cellular models (see Figure 25.9). The omics data from these models is expected to allow biological target identification and validation. This information will facilitate personalized therapy for a specific patient depending on the patient's genetic background. 


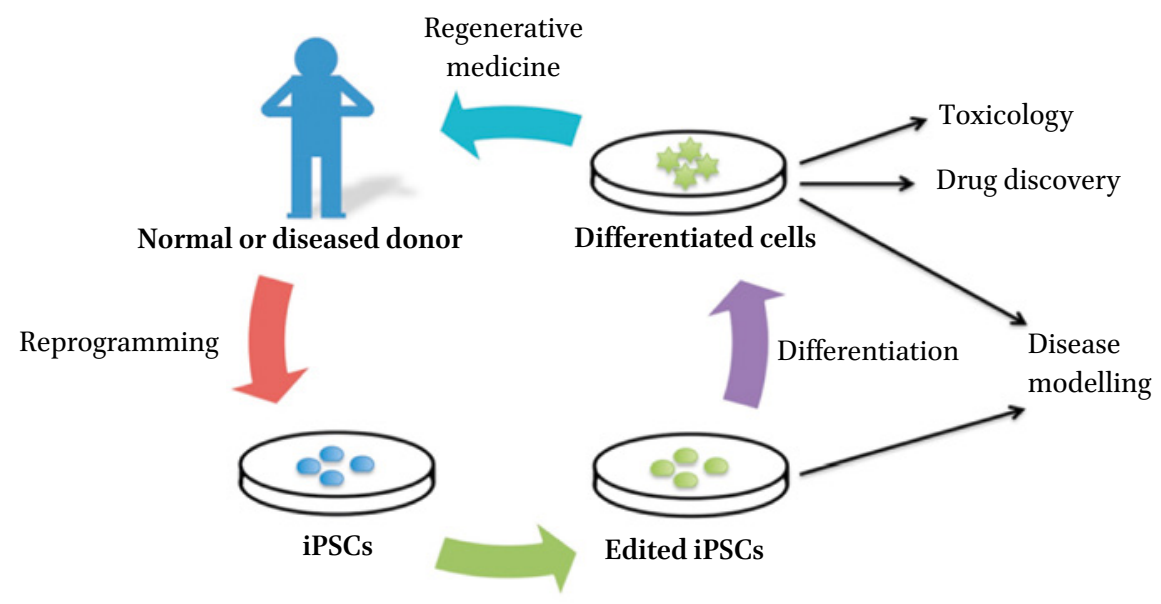

Gene editing

FIGURE 25.8 Modern cell reprogramming and gene editing tools, allowing modifications of patient-specific iPSCs for use in disease research, toxicology, and screening, in addition to the possibility of cell therapy.

IMAGE TAKEN FROM SEAH ET AL. (2015)

Clinical
observation
/ monitoring

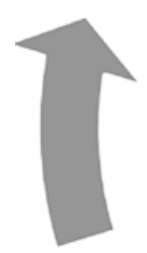

$$
\begin{gathered}
\text { Evidence } \\
\text { based } \\
\text { personalized } \\
\text { therapy }
\end{gathered}
$$

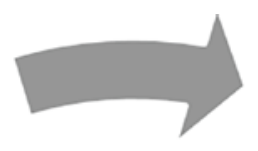

in vitro

patient

specific

mechanistic

investigations

FIGURE 25.9 The paradigm shift towards clinical, observations-based, mechanistic investigations in vitro, using advanced tools of cell culture and omics. These should provide potential biomarkers and targets for exploitation in evidence-based personalized therapy and follow-up. 
Clinical observations combined with the omics information, mechanisms, and biomarkers will iterate the whole process in modern systems toxicology. The impact of this approach is, no doubt, beyond toxicology in other fields of health, medicine, drug development, and basic sciences.

\section{References}

Adeleye, Y., M. Andersen, R. Clewell, M. Davies, M. Dent, S. Edwards, P. Fowler, S. Malcomber, B. Nicol, A. Scott, B. Sun, C. Westmoreland, A. White, Q. Zhang and P.L. Carmichael (2014). Implementing Toxicity Testing in the 21st Century (TT21C): Making Safety Decisions Using Toxicity Pathways, and Progress in a Prototype Risk Assessment. Toxicology, 332, pp. 102-111.

Alepee, N., A. Bahinski, M. Daneshian, De B. Wever, E. Fritsche, A. Goldberg, J. Hansmann, T. Hartung, J. Haycock, H. Hogberg, L. Hoelting, J.M. Kelm, S. Kadereit, E. McVey, R. Landsiedel, M. Leist, M. Lübberstedt, F. Noor, C. Pellevoisin, D. Petersohn, U. Pfannenbecker, K. Reisinger, T. Ramirez, B. Rothen-Rutishauser, M. SchäferKorting, K. Zeilinger and M.G. Zurich (2014). State-of-the-art of 3 D Cultures (Organs on a Chip) in Safety Testing and Pathophysiology. Alternatives to Animal Experimentation, 31, pp. 441-477.

Ankley, G.T., R.S. Bennett, R.J. Erickson, D.J. Hoff, M.W. Hornung, R.D. Johnson, D.R. Mount, J.W. Nichols, C.L. Russom, P.K. Schmieder, J.A. Serrrano, J.E. Tietge and D.L. Villeneuve (2010). Adverse Outcome Pathways: A Conceptual Framework to Support Ecotoxicology Research and Risk Assessment. Environmenal Toxicology and Chemistry, 29(3), pp. 730-741.

Asgari, S., B. Pournasr, G.H. Salekdeh, A. Ghodsizadeh, M. Ott and H. Baharvand (2010). Induced Pluripotent Stem Cells: A New Era for Hepatology. Journal of Hepatology, 53, pp. $738-751$.

Attene-Ramos, M.S., N. Miller, R. Huang, S. Michael, M. Itkin, R.J. Kavlock, C.P. Austin, P. Shinn, A. Simeonov, R.R. Tice and M. Xia (2013). The Tox21 Robotic Platform for the Assessment of Environmental Chemicals: From Vision to Reality. Drug Discovery Today, 18(15-16), pp. 716-723.

Bale, S.S., L. Vernetti, N. Senutovitch, R. Jindal, M. Hegde, A. Gough, W.J. McCarty, A. Bakan, A. Bhushan, T.Y. Shun, I. Golberg, R. DeBiasio, B.O. Usta, D.L. Taylor and M.L. Yarmush (2014). In Vitro Platforms for Evaluating Liver Toxicity. Experimental Biology and Medicine (Maywood), 239, pp. 1180-1191.

Baudoin, R., A. Corlu, L. Griscom, C. Legallais, and E. Leclerc (2007). Trends in the Development of Microfluidic Cell Biochips for In Vitro Hepatotoxicity. Toxicology In Vitro, 21, pp. 535-544. 
Becker, R.A., G.T. Ankley, S.W. Edwards, S.W. Kennedy, I. Linkov, B. Meek, M. Sachana, H. Segner, B. Van Der Burg, D.L. Villeneuve, H. Watanabe and T.S. Barton-Maclaren (2015). Increasing Scientific Confidence in Adverse Outcome Pathways: Application of Tailored Bradford-Hill Considerations for Evaluating Weight of Evidence. Regulatory Toxicology and Pharmacology, 72, pp. 514-537.

Bhatia, S.N., and D.E. Ingber (2014). Microfluidic Organs on Chips. Nature Biotechnology, 32, pp. 76o-772.

Billiet, T., E. Gevaert, T. De Schryver, M. Cornelissen and P. Dubruel (2014). The 3D Printing of Gelatin Methacrylamide Cell-laden Tissue-engineered Constructs with High Cell Viability. Biomaterials, 35, 49-62.

Bissell, M.J. (2007). Architecture Is the Message: The Role of Extracellular Matrix and ${ }_{3}$ D Structure in Tissue-specific Gene Expression and Breast Cancer. Pezcoller Foundation Journal, 16(29), pp. 2-17.

Bissell, M.J., H.G. Hall, and G. Parry (1982). How Does the Extracellular Matrix Direct Gene Expression?.Journal of Theoretical Biology, 99(1), pp. 31-68.

Blaauboer, B.J. and M.E. Andersen (2007). The Need for a New Toxicity Testing and Risk Analysis Paradigm to Implement REACH or Any Other Large Scale Testing Initiative. Archives of Toxicology, 81(5), pp. 385-387.

Bouhifd, M., M.E. Andersen, C. Baghdikian, K. Boekelheide, K.M. Crofton, A.J. Fornace Jr., A. Kleensang, H. Li, C. Livi, A. Maertens, P.D. McMullen, M. Rosenberg, R. Thomas, M. Vantangoli, J.D. Yager, L. Zhao and T. Hartung (2015). The Human Toxome Project. Alternatives to Animal Experimentation, 32(2), pp. 112-124.

Bucher, J.R. (2002). The National Toxicology Program Rodent Bioassay: Designs, Interpretations, and Scientific Contributions. Annals of the New York Academy of Sciences, 982, pp. 198-207.

Chang, X., N. Kleinstreuer, P. Ceger, J. Hsieh, D. Allen and W. Casey (2015). Application of Reverse Dosimetry to Compare In Vitro and In Vivo Estrogen Receptor Activity. Applied In Vitro Toxicology, 1(1), pp. 33-44.

Coecke, S., O. Pelkonen, S.B. Leite, U. Bernauer, J.G. Bessems, F.Y. Bois, U. GundertRemy, G. Loizou, E. Testai and J.M. Zaldivar (2013). Toxicokinetics as a Key to the Integrated Toxicity Risk Assessment Based Primarily on Non-animal Approaches. Toxicology In Vitro, 27, pp. 1570-1577.

Cros, A.F.A. (1863). Action de L'alcool Amylique sur L'organism. Faculté de Médecine Strasbourg.

Crum-Brown, A., and T.R. Fraser (1869). On the Connection Between Chemical Constitution and Physiological Action. Part I. Transactions of the Royal Society of Edinburgh, 25, pp. 257-274.

Edwards, S.W. and R.J. Preston (2008). Systems Biology and Mode of Action Based Risk Assessment. Toxicological Sciences, 106, pp. 312-318. 
Edwards, S.W., Y.M. Tan, D.L. Villeneuve, M.E. Meek and C.A. McQueen (2016). Adverse Outcome Pathways-organizing Toxicological Information to Improve Decision Making. Journal of Pharmacology and Experimental Therapeutics, 356(1), pp. 170-181.

Enoch, S.J., M.T. Cronin, C.M. Ellison (2011). The Use of a Chemistry-based Profiler for Covalent DNA Binding in the Development of Chemical Categories for Read-Across for Genotoxicity. Alternatives to Laboratory Animals, 39(2), pp. 131-145.

European Chemicals Agency (2017). Read-Across Assessment Framework (RAAF). [online] Available at: https://echa.europa.eu/documents/10162/13628/raaf_en.pdf [Accessed 9 March 2018].

Ewart, L., M. Aylott, M. Deurinck, M. Engwall, D.J. Gallacher, H. Geys, P. Jarvis, H. Ju, D. Leishman, L. Leong, N. McMahon, A. Mead, P. Milliken, W. Suter, A. Teisman, K. Van Ammel, H.M. Vargas, R. Wallis and J.P. Valentin (2014). The Concordance Between Nonclinical and Phase I Clinical Cardiovascular Assessment from a Cross-company Data Sharing Initiative. Toxicological Sciences, 142(2), pp. 427-435.

Flaherty, E.K. and K.J. Brennand (2015). Using hipscs to Model Neuropsychiatric Copy Number Variations (Cnvs) Has Potential to Reveal Underlying Disease Mechanisms. Brain Research, 1655, pp. 283-293.

Gaj, T., C.A. Gersbach, and C.F. Barbas 3rd (2013). ZFN, TALEN, and CRISPR/Casbased Methods for Genome Engineering. Trends in Biotechnology, 31, pp. 397-405.

Garcia-Reyero, N. (2015). Are Adverse Outcome Pathways Here to Stay? Environmental Science and Technology, 49, pp. 3-9.

Gasparri, F. (2009). An Overview of Cell Phenotypes in HCS: Limitations and Advantages. Expert Opinions in Drug Discovery, 4, pp. 643-657.

Gevaert, E., L. Dolle, T. Billiet, P. Dubruel, L. van Grunsven, A. van Apeldoorn and R. Cornelissen (2014). High Throughput Micro-well Generation of Hepatocyte Microaggregates for Tissue Engineering. PLoS One, 9, p. e105171.

Ghodsizadeh, A., A. Taei, M. Totonchi, A. Seifinejad, H. Gourabi, B. Pournasr, N. Aghdami, R. Malekzadeh, N. Almadani, G.H. Salekdeh and H. Baharvand (2010). Generation of Liver Disease-specific Induced Pluripotent Stem Cells Along with Efficient Differentiation to Functional Hepatocyte-like Cells. Stem Cell Reviews, 6, pp. $622-632$.

Gocht, T., E. Berggren, H.J. Ahr, I. Cotgreave, M.T. Cronin, G. Daston, B. Hardy, E. Heinzle, J. Hescheler, D.J. Knight, C. Mahony, M. Peschanski, M. Schwarz, R.S. Thomas, C. Verfaillie, A. White and M. Whelan (2015). The SEURAT-1 Approach Towards Animal Free Human Safety Assessment. Alternatives to Animal Experimentation, 32(1), pp. 9-24.

Godoy, P., N.J. Hewitt, U. Albrecht, M.E. Andersen, N. Ansari, S. Bhattacharya, J.G. Bode, J. Bolleyn, C. Borner, J. Bottger, A. Braeuning, R.A. Budinsky, B. Burkhardt, N.R. Cameron, G. Camussi, C.S. Cho, Y.J. Choi, R.J. Craig, U. Dahmen, G. Damm, O. Dirsch, M.T. Donato, J. Dong, S. Dooley, D. Drasdo, R. Eakins, K.S. Ferreira, V. Fonsato, J. 
Fraczek, R. Gebhardt, A. Gibson, M. Glanemann, C.E. Goldring, M.J. Gómez-Lechón, G.M. Groothuis, L. Gustavsson, C. Guyot, D. Hallifax, S. Hammad, A. Hayward, D. Häussinger, C. Hellerbrand, P. Hewitt, S. Hoehme, H.G. Holzhütter, J.B. Houston, J. Hrach, K. Ito, H. Jaeschke, V. Keitel, J.M. Kelm, B. Kevin, C. Kordes, G.A. KullakUblick, E.L. LeCluyse, P. Lu, J. Luebke-Wheeler, A. Lutz, D.J. Maltman, M. Matz-Soja, P. McMullen, I. Merfort, S. Messner, C. Meyer, J. Mwinyi, D.J. Naisbitt, A.K. Nussler, P. Olinga, F. Pampaloni, J. Pi, L. Pluta, S.A. Przyborski, A. Ramachandran, V. Rogiers, C. Rowe, C. Schelcher, K. Schmich, M. Schwarz, B. Singh, E.H. Stelzer, B. Stieger, R. Stöber, Y. Sugiyama, C. Tetta, W. Thasler, T. Vanhaecke, M. Vinken, T.S. Weiss, A. Widera, C.G. Woods, J.J. Xu, K.M. Yarborough and J.G. Hengstler (2013). Recent Advances in ${ }_{2} \mathrm{D}$ and ${ }_{3} \mathrm{D}$ In Vitro Systems Using Primary Hepatocytes, Alternative Hepatocyte Sources and Non-parenchymal Liver Cells and Their Use in Investigating Mechanisms Of Hepatotoxicity, Cell Signaling and ADME. Archives of Toxicology, 87, pp. 1315-1530.

Groothuis, F.A., M.B. Heringa, B. Nicol, J.L. Hermens, B.J. Blaauboer and N.I. Kramer (2015). Dose Metric Considerations in In Vitro Assays to improve Quantitative In Vitro-In Vivo Dose Extrapolations. Toxicology, 332, pp. 30-40.

Gunness, P., D. Mueller, V. Shevchenko, E. Heinzle, M. Ingelman-Sundberg and F. Noor (2013). 3D Organotypic Cultures of Human HepaRG Cells: A Tool for In Vitro Toxicity Studies. Toxicological Sciences 133(1), pp. 67-78.

Hamon, J., M. Renner, M. Jamei, A. Lukas, A. Kopp-Schneider and F.Y. Bois (2015). Quantitative In Vitro to In Vivo Extrapolation of Tissues Toxicity. Toxicology In Vitro, 30(1A), pp. 203-216.

Hartung, T. (2009). Per Aspirin Ad Astra. Alternatives to Laboratory Animals, 37(2), pp. 45-47.

Hartung, T. and G. Daston (2009). Are In Vitro Tests Suitable for Regulatory Use?. Toxicological Sciences, 111, pp. 233-237.

Hartung, T. and M. McBride (2011). Food for Thought ... on mapping the human toxome. Alternatives to Animal Experimentation, 28 (2), pp. 83-93.

Hay, M., D.W. Thomas, J.L. Craighead, C. Economides and J. Rosenthal (2014). Clinical Development Success Rates for Investigational Drugs. Nature Biotechnology, 32, pp. $40-51$.

Horton, R. (2004). Vioxx, The Implosion of Merck and Aftershocks at the FDA. Lancet, 364, pp. $1995^{-1996 .}$

Howden, S.E., J.P. Maufort, B.M. Duffin, A.G. Elefanty, E.G. Stanley, and J.A. Thomson (2015). Simultaneous Reprogramming and Gene Correction of Patient Fibroblasts. Stem Cell Reports, 5(6), pp. 1109-1118.

Hsieh, J.H., R. Huang, J.A. Lin, A. Sedykh, J. Zhao, R.R. Tice, R.S. Paules, M. Xia and S.S. Auerbach (2017). Real-time Cell Toxicity Profiling of Tox21 10K Compounds Reveals Cytotoxicity Dependent Toxicity Pathway Linkage. PLoS One, 12(5), p. e0177902. 
Ideker, T., T. Galitski and L. Hood (2001). A New Approach to Decoding Life: Systems Biology. Annual Review of Genomics and Human Genetics, 2, pp. 343-372.

Johnson, M.A. and G.M. Maggiora, eds. (1990). Concepts and applications of molecular similarity. 1st ed. Wiley.

Jones, H.M., K. Mayawala and P. Poulin (2013). Dose Selection Based on Physiologically Based Pharmacokinetic (PBPK) Approaches. American Association of Pharmaceutical Scientists Journal, 15(2), pp. 377-387.

Khetani, S.R. and S.N. Bhatia (2008). Microscale Culture of Human Liver Cells for Drug Development. Nature Biotechnology, 26, pp. 120-126.

Kim, J.S. (2016). Genome Editing Comes of Age. Nature Protocols, 11(9), pp. 1573-1578.

Kitano, H. (2002). Computational Systems Biology. Nature, 420, pp. 206-210.

Kleensang, A., A. Maertens, M. Rosenberg, S. Fitzpatrick, J. Lamb, S. Auerbach, R. Brennan, K.M. Crofton, B. Gordon, A.J. Fornace Jr., K. Gaido, D. Gerhold, R. Haw, A. Henney, A. Ma'ayan, M. McBride, S. Monti, M.F. Ochs, A. Pandey, R. Sharan, R. Stierum, S. Tugendreich, C. Willett, C. Wittwehr, J. Xia, G.W. Patton, K. Arvidson, M. Bouhifd, H.T. Hogberg, T. Luechtefeld, L. Smirnova, L. Zhao, Y. Adeleye, M. Kanehisa, P. Carmichael, M.E. Andersen and T. Hartung (2014). T4 Workshop Report: Pathways of Toxicity. Alternatives to Animal Experimentation, 31(1), pp. 53-61.

Klein, S., S. Maggioni, J. Bucher, D. Mueller, J. Niklas, V. Shevchenko, K. Mauch, E. Heinzle and F. Noor (2015). In Silico Modeling for the Prediction of Dose and Pathway Related Adverse Effects in Humans from In Vitro Repeated-dose Studies. Toxicological Sciences, 149(1), pp. 55-66.

Klein, S., D. Mueller, V. Schevchenko and F. Noor (2014). Long-term Maintenance of HepaRG Cells in Serum-free Conditions and Application in a Repeated Dose Study. Journal of Applied Toxicology, 34(10), pp. 1078-1086.

Knight-Schrijver, V.R., V. Chelliah, L. Cucurull-Sanchez and N. Le Novère (2016). The Promise of Quantitative Systems Pharmacology Modelling for Drug Development. Computational and Structural Biotechnology Journal, 14, pp. 363-370.

Kola, I. and J. Landis (2004). Can the Pharmaceutical Industry Reduce Attrition Rates?. Nature Reviews Drug Discovery, 3(8), pp. 711-716.

Komor, A.C., A.H. Badran and D.R. Liu (2017). CRISPR-Based Technologies for the Manipulation of Eukaryotic Genomes. Cell, 168(1-2), pp. 20-36.

Krewski, D., D. Acosta Jr., M. Andersen, H. Anderson, J.C. Bailar 3 rd, K. Boekelheide, R. Brent, G. Charnley, V.G. Cheung, S. Green Jr., K.T. Kelsey, N.I. Kerkvliet, A.A. Li, L. McCray, O. Meyer, R.D. Patterson, W. Pennie, R.A. Scala, G.M. Solomon, M. Stephens, J. Yager and L. Zeise (2010). Toxicity Testing in the 21st Century: A Vision and a Strategy. Journal of Toxicology and Environmental Health Part B Critical Reviews, 13(2-4), pp. 51-138.

Landesmann, B., M. Mennecozzi, E. Berggren and M. Whelan (2013). Adverse Outcome Pathway-based Screening Strategies for an Animal-free Safety Assessment of Chemicals. Alternatives to Laboratory Animals, 41, pp. 461-471. 
Lang, L. (2005). Valdecoxib (Bextra) Withdrawal Leaves Pain Relief Treatment Gap. Gastroenterology, 128, pp. 1769-1770.

Langley, G.R., I.M. Adcock, F. Busquet, K.M. Crofton, E. Csernok, C. Giese, T. Heinonen, K. Herrmann, M. Hofmann-Apitius, B. Landesmann, L.J. Marshall, E. McIvor, A.R. Muotri, F. Noor, K. Schutte, T. Seidle, A. van de Stolpe, H. Van Esch, C. Willett and G. Woszczek (2017), Towards a 21st-century Roadmap for Biomedical Research and Drug Discovery: Consensus Report and Recommendations. Drug Discovery Today, 22(2), pp. 327-339.

Le Beyec, J., R. Xu, S.Y. Lee, C.M. Nelson, A. Rizki, J. Alcaraz and M.J. Bissell (2007). Cell Shape Regulates Global Histone Acetylation in Human Mammary Epithelial Cells. Experimental Cell Research, 313(14), pp. 3066-3075.

Li, M., K. Suzuki, N.Y. Kim, G.H. Liu and J.C. Izpisua Belmonte (2014). A Cut Above the Rest: Targeted Genome Editing Technologies in Human Pluripotent Stem cells. Journal of Biological Chemistry, 289, pp. 4594-4599.

Martignoni, M., G.M. Groothuis and R. de Kanter (2006). Species Differences Between Mouse, Rat, Dog, Monkey, and Human CYP-mediated Drug Metabolism, Inhibition, and Induction. Expert Opinion on Drug Metabolism and Toxicology, 2, pp. 875-894.

Marx, U., H. Walles, S. Hoffmann, G. Lindner, R. Horland, F. Sonntag, U. Klotzbach, D. Sakharov, A. Tonevitsky and R. Lauster (2012). "Human on a Chip Developments": A Translational Cutting-edge Alternative to Systemic Safety Assessment and Efficiency Evaluation of Substances in Laboratory Animals and Man?. Alternatives to Laboratory Animals, 40, pp. 235-257.

Materne, E.M., I. Maschmeyer, A.K. Lorenz, R. Horland, K.M. Schimek, M. Busek, F. Sonntag, R. Lauster and U. Marx (2015a). The Multi-organ Chip. A Microfluidic Platform for Long-term Multi-tissue Coculture. Journal of Visualized Experiments, p. e52526.

Materne, E.M., A.P. Ramme, A.P. Terrasso, M. Serra, P.M. Alves, C. Brito, D.A. Sakharov, A.G. Tonevitsky, R. Lauster and U. Marx (2015b). A Multi-Organ Chip Co-culture of Neurospheres and Liver Equivalents for Long-term Substance Testing. Journal of Biotechnology, 205, pp. 36-46.

McCracken, K.W., E.M. Cata, C.M. Crawford, K.L. Sinagoga, M. Schumacher, B.E. Rockich, Y.H. Tsai, C.N. Mayhew, J.R. Spence, Y. Zavros and J.M. Wells (2014). Modeling Human Development and Disease in Pluripotent Stem-cell-derived Gastric Organoids. Nature, 516(7531), pp. 400-404.

Mueller, D., E. Heinzle and F. Noor (2013). 3D Hepatic In Vitro Models as Tools for Toxicity Studies. Current Tissue Engineering, 2, pp. 78-89.

Mueller, D., A. Koetemann and F. Noor (2011a). Organotypic Cultures of HepG2 for In Vitro Toxicity Studies. Journal of Bioengineering and Biomedical Science, S2:002.

Mueller, D., L. Kramer, E. Hoffmann, S. Klein and F. Noor (2014). 3D Organotypic HepaRG Cultures as In Vitro Model for Acute and Repeated Dose Toxicity Studies. Toxicology In Vitro, 28, pp. 104-112. 
Mueller, D., U. Muller-Vieira, K.M. Biemel, G. Tascher, A.K. Nussler and F. Noor (2012). Biotransformation of Diclofenac and Effects on the Metabolome of Primary $\mathrm{Hu}-$ man Hepatocytes upon Repeated Dose Exposure. European Journal of Pharmaceutical Sciences, 45, pp. 716-724.

Mueller, D., G. Tascher, U. Muller-Vieira, D. Knobeloch, A.K. Nuessler, K. Zeilinger, E. Heinzle and F. Noor (2011b). In-depth Physiological Characterization of Primary Human Hepatocytes in a $3 \mathrm{D}$ Hollow-fiber Bioreactor. Journal of Tissue Engineering and Regenerative Medicine, 5(8), pp. e207-e218.

Mullin, R. (2014). Tufts Study Finds Big Rise in Cost of Drug Development. Chemical and Engineering News. [online] Available at: http://cen.acs.org/articles/92/web/2014/11/ Tufts-Study-Finds-Big-Rise.html [Accessed 9 March 2018].

Nicholas, J.S. (1961). Ross Granville Harrison. Biographical Memoirs National Academy of Sciences, 35, pp. 132-162.

Noor, F. (2015). A Shift in Paradigm Towards Human Biology-based Systems for Cholestatic-liver Diseases. The Journal of Physiology, 593(23), pp. 5043-5055.

Noor, F., J. Niklas, U. Muller-Vieira and E. Heinzle (2009). An Integrated Approach to Improved Toxicity Prediction for the Safety Assessment During Preclinical Drug DevelopmentUsingHep G2 Cells. ToxicolologyandAppliedPharmacolology, 237,pp. 221-231.

OECD (2013). Guidance Document on Developing and Assessing Adverse Outcome Pathways. Series on Testing and Assessment, 184. Paris: OECD Publishing. [online] Available at: http://www.oecd.org/chemicalsafety/testing/series-testing -assessment-publications-number.htm [Accessed 9 March 2018].

Olson, H., G. Betton, D. Robinson, K. Thomas, A. Monro, G. Kolaja, P. Lilly, J. Sanders, G. Sipes, W. Bracken, M. Dorato, K. Van Deun, P. Smith, B. Berger and A. Heller (2000). Concordance of the Toxicity of Pharmaceuticals in Humans and in Animals. Regulatory Toxicology and Pharmacolology, 32(1), pp. 56-67.

Onakpoya, I.J., C.J. Heneghan and J.K. Aronson, (2016). Post-marketing Withdrawal of 462 Medicinal Products Because of Adverse Drug Reactions: A Systematic Review of the World Literature. BMC Medicine 14, pp. 10-21.

Organisation for Economic Co-operation and Development (OECD) (2012). The Adverse Outcome Pathway for Skin Sensitization Initiated by Covalent Binding to Proteins. Part I: Scientific Evidence. Series on Testing and Assessment, 168. Paris: OECD Publishing. [online] Available at: http://www.oecd.org/officialdocuments/ publicdisplaydocumentpdf/?cote $=\mathrm{env} / \mathrm{jm} / \mathrm{mono}(2012) 10 /$ part1\&doclanguage $=\mathrm{en}$ [Accessed 9 March 2018].

Paine, A.J. and E. Andreakos (2004). Activation of Signalling Pathways During Hepatocyte Isolation: Relevance to Toxicology In Vitro. Toxicology In Vitro, 18, pp. 187-193.

Patlewicz, G., T. Simon, K. Goyak, R.D. Phillips, J.C. Rowlands, S.D. Seidel and R.A. Becker (2013). Use and Validation of HT/HC Assays to Support 21st Century Toxicity Evaluations. Regulatory Toxicology and Pharmacology, 65, pp. 259-268. 
Perkins, E.J., P. Antczak, L. Burgoon, F. Falciani, N. Garcia-Reyero, S. Gutsell, G. Hodges, A. Kienzler, D. Knapen, M. McBride and C. Willett (2015). Adverse Outcome Pathways for Regulatory Applications: Examination of Four Case Studies with Different Degrees of Completeness and Scientific Confidence. Toxicological Sciences, 148(1), pp. 14-25.

Poulin, P. (2013). Prediction of Total Hepatic Clearance by Combining Metabolism, Transport, and Permeability Data in the In Vitro-In Vivo Extrapolation Methods: Emphasis on an Apparent Fraction Unbound in Liver for Drugs. Journal of Pharmaceutical Sciences, 102, pp. 2085-2095.

Poulin, P. and S. Haddad (2013). Toward a New Paradigm for the Efficient In Vitro-In Vivo Extrapolation of Metabolic Clearance in Humans from Hepatocyte Data.Journal of Pharmaceutical Sciences, 102, pp. 3239-3251.

Poulin, P., D.M. Dambach, D.H. Hartley, K. Ford, F.P. Theil, E. Harstad, J. Halladay, E. Choo, J. Boggs, B.M. Liederer, B. Dean and D. Dolores (2013a). An Algorithm for Evaluating Potential Tissue Drug Distribution in Toxicology Studies from Readily Available Pharmacokinetic Parameters. Journal of Pharmaceutical Sciences, 102, pp. 3816-3829.

Poulin, P., C.E. Hop, L. Salphati and B.M. Liederer (2013b). Correlation of Tissue-plasma Partition Coefficients Between Normal Tissues and Subcutaneous Xenografts of Human Tumor Cell Lines in Mouse as a Prediction Tool of Drug Penetration in Tumors. Journal of Pharmaceutical Sciences, 102, pp. 1355-1369.

Ramaiahgari, S.C., M.W. den Braver, B. Herpers, V. Terpstra, J.N. Commandeur, B. van de Water and L.S. Price (2014). A 3D In Vitro Model of Differentiated HepG2 Cell Spheroids with Improved Liver-like Properties for Repeated Dose High-throughput Toxicity Studies. Archives of Toxicology, 88, pp. 1083-1095.

Rotroff, D.M., B.A. Wetmore, D.J. Dix, S.S. Ferguson, H.J. Clewell, K.A. Houck, E.L. Lecluyse, M.E. Andersen, R.S. Judson, C.M. Smith, M.A. Sochaski, R.J. Kavlock, F. Boellmann, M.T. Martin, D.M. Reif, J.F. Wambaugh and R.S. Thomas (2010). Incorporating Human Dosimetry and Exposure into High-throughput In Vitro Toxicity Screening. Toxicological Sciences, 117, pp. 348-358.

Sacks, L.V., H.H. Shamsuddin, Y.I. Yasinskaya, K. Bouri, M.L. Lanthier and R.E. Sherman (2014). Scientific and Regulatory Reasons for Delay and Denial of FDA Approval of Initial Applications for New Drugs, 2000-2012. Journal of the American Medical Association, 311(4), pp. 378-384.

Schwartz, R.E., H.E. Fleming, S.R. Khetani and S.N. Bhatia (2014). Pluripotent Stem Cell-derived Hepatocyte-like Cells. Biotechnology Advances, 32(2), pp. 504-513.

Seah, Y.F.S., C.A. EL Farran, T. Warrier, J. Xu and Y.H. Loh (2015). Induced Pluripotency and Gene Editing in Disease Modeling: Perspectives and Challenges. International Journal of Molecular Sciences, 16(12), pp. 28614-28634.

Selye, H. (1956). The stress of life. New York: McGraw-Hill Book Co. 
Sheldon, L.S., and E.A. Cohen Hubal (2009). Exposure as Part of a Systems Approach for Assessing Risk. Environmental Health Perspectives, 117, pp. 119-1194.

Shinde, V., P. Sureshkumar, I. Sotiriadou, J. Hescheler and A. Sachinidis (2016). Human Embryonic and induced Pluripotent Stem Cell Based Toxicity Testing Models: Future Applications in New Drug Discovery. Current Medicinal Chemistry, 23(30), pp. 3495-3509.

Shtrichman, R., I. Germanguz and J. Itskovitz-Eldor (2013). Induced Pluripotent Stem Cells (ipscs) Derived from Different Cell Sources and Their Potential for Regenerative and Personalized Medicine. Current Molecular Medicine, 13, pp. 792-805.

Siller, R., S. Greenhough, I.H. Park and G.J. Sullivan (2013). Modelling Human Disease with Pluripotent Stem Cells. Current Gene Therapy, 13, pp. 99-110.

Sirenko, O., J. Hesley, I. Rusyn and E.F. Cromwell (2014). High-content Assays for Hepatotoxicity Using Induced Pluripotent Stem Cell-derived Cells. Assay and Drug Development Technologies, 12(1), pp. 43-54.

Smith, D.A. and E.F. Schmid (2006). Drug Withdrawals and the Lessons Within. Current Opinion in Drug Discovery and Development, 9 (1), pp. 38-46.

Sobels, F.H. (1977). Some Problems Associated with the Testing for Environmental Mutagens and a Perspective for Studies in "Comparative Mutagenesis". Mutation Research, 46(4), 2, pp. 245-26o.

Spencer, V.A., R. Xu and M.J. Bissell (2007). Extracellular Matrix, Nuclear, and Chromatin Structure and Gene Expression in Normal Tissues and Malignant Tumors: A Work in Progress. Advances in Cancer Research, 97, pp. 275-294.

Sung, J.H., B. Srinivasan, M.B. Esch, W.T. McLamb, C. Bernabini, M.L. Shuler and J.J. Hickman (2014). Using Physiologically-based Pharmacokinetic-guided "Body on a Chip" Systems to Predict Mammalian Response to Drug and Chemical Exposure. Experimental Biological and Medicine (Maywood), 239, pp. 1225-1239.

Suzuki, K., C. Yu, J. Qu, M. Li, X. Yao, T. Yuan, A. Goebl, S. Tang, R. Ren, E. Aizawa, F. Zhang, X. Xu, R.D. Soligalla, F. Chen, J. Kim, N.Y. Kim, H.K. Liao, C. Benner, C.R. Esteban, Y.Jin, G.H. Liu, Y. Li and J.C. Izpisua Belmonte (2014). Targeted Gene Correction Minimally Impacts Whole-genome Mutational Load in Human-disease-specific Induced Pluripotent Stem Cell Clones. Cell Stem Cell, 15(1), pp. 31-36.

Teorell, T. (1937). Kinetics of Distribution of Substances Administered to the Body. Archives Internationales de Pharmacodynamie et de Thérapie, 57, pp. 205-240.

Tobita, T., J. Guzman-Lepe and A.C. de l'Hortet (2015). From Hacking the Human Genome to Editing Organs. Organogenesis, 11(4), pp. 173-182.

Tolosa, L., A. Carmona, J.V. Castell, M.J. Gomez-Lechon and M.T. Donato (2014). Highcontent Screening of Drug-induced Mitochondrial Impairment in Hepatic Cells: Effects of Statins. Archives of Toxicology, 89(10), pp. 1847-1860.

Tseng, Y.J., A.J. Hopfinger and E.X. Esposito (2012). The Great Descriptor Melting Pot: Mixing Descriptors for the Common Good of QSAR Models. Journal of Computer Aided Molecular Design, 26(1), pp. 39-43. 
van Grunsven, L.A. (2017). 3D In Vitro Models of Liver Fibrosis. Advanced Drug Delivery Reviews, 121, pp. 133-146.

van Vliet, E., M. Daneshian, M. Beilmann, A. Davies, E. Fava, R. Fleck, Y. Jule, M. Kansy, S. Kustermann, P. Macko, W.R. Mundy, A. Roth, I. Shah, M. Uteng, B. van de Water, T. Hartung and M. Leist (2014). Current Approaches and Future Role of High Content Imaging in Safety Sciences and Drug Discovery. Alternatives to Animal Experimentation, 31(4), pp. 479-493.

Vedani, A., M. Dobler, M.A. Lill (2006). The Challenge of Predicting Drug Toxicity In Silico. Basic and Clinical Pharmacology and Toxicology, 99(3), pp. 195-208.

Vernetti, L.A., A. Vogt, A. Gough and D.L. Taylor (2017). Evolution of Experimental Models of the Liver to Predict Human Drug Hepatotoxicity and Efficacy. Clinics in Liver Disease, 21(1), pp. 197-214.

Villeneuve, D.L., D. Crump, N. Garcia-Reyero, M. Hecker, T.H. Hutchinson, C.A. LaLone, B. Landesmann, T. Lettieri, S. Munn, M. Nepelska, M.A. Ottinger, L. Vergauwen and M. Whelan (2014a). Adverse Outcome Pathway (AOP) Development I: Strategies and Principles. Toxicological Sciences, 142(2), pp. 312-320.

Villeneuve, D.L., D. Crump, N. Garcia-Reyero, M. Hecker, T.H. Hutchinson, C.A. LaLone, B. Landesmann, T. Lettieri, S. Munn, M. Nepelska, M.A. Ottinger, L. Vergauwen and M. Whelan (2014b). Adverse Outcome Pathway Development II: Best Practices. Toxicological Sciences, 142(2), pp. 321-330.

Vinken, M., B. Landesmann, M. Goumenou, S. Vinken, I. Shah, H. Jaeschke, C. Willett, M. Whelan and V. Rogiers (2013). Development of an Adverse Outcome Pathway from Drug-mediated Bile Salt Export Pump Inhibition to Cholestatic Liver Injury. Toxicological Sciences, 136(1), pp. 97-106.

Ware, B.R., D.R. Berger and S.R. Khetani (2015). Prediction of Drug Induced Liver Injury in Micropatterned Co-cultures Containing iPsC-derived Human Hepatocytes. Toxicological Sciences, 145(2), pp. 252-262.

Waring, M.J., J. Arrowsmith, A.R. Leach, P.D. Leeson, S. Mandrell, R.M. Owen, G. Pairaudeau, W.D. Pennie, S.D. Pickett, J.B. Wang, O. Wallace and A. Weir (2015). An Analysis of the Attrition of Drug Candidates from Four Major Pharmaceutical Companies. Nature Reviews Drug Discovery, 4(7), pp. 475-486.

Wetmore, B.A., J.F. Wambaugh, S.S. Ferguson, M.A. Sochaski, D.M. Rotroff, K. Freeman, H.J. Clewell 3rd, D.J. Dix, M.E. Andersen, K.A. Houck, B. Allen, R.S. Judson, R. Singh, R.J. Kavlock, A.M. Richard and R.S. Thomas (2012). Integration of Dosimetry, Exposure, and High-throughput Screening Data in Chemical Toxicity Assessment. Toxicological Sciences, 125(1), pp. 157-174.

Willett, C., J. Caverly Rae, K.O. Goyak, B. Landesmann, G. Minsavage and C. Westmoreland (2014). Pathway-based Toxicity: History, Current Approaches and Liver Fibrosis and Steatosis as Prototypes. Alternatives to Animal Experimentation, 31, pp. 407-421.

Woolbright, B.L., K. Dorko, D.J. Antoine, J.I. Clarke, P. Gholami, F. Li, S.C. Kumer, T.M. Schmitt, J. Forster, F. Fan, R.E. Jenkins, B.K. Park, B. Hagenbuch, M. Olyaee and H. 
Jaeschke (2015). Bile Acid-induced Necrosis in Primary Human Hepatocytes and in Patients with Obstructive Cholestasis. Toxicology and Applied Pharmacology, 283, pp. $168-177$.

Xu, R., V.A. Spencer and M.J. Bissell (2007). Extracellular Matrix-regulated Gene Expression Requires Cooperation of SWI/SNF and Transcription Factors. Journal of Biological Chemistry, 282, pp. 14992-14999.

Yoon, M., A. Efremenko, B.J. Blaauboer and H.J. Clewell (2014). Evaluation of Simple In Vitro to In Vivo Extrapolation Approaches for Environmental Compounds. Toxicology In Vitro, 28, pp. 164-170. 